\title{
A CONSULTORIA COMO OPORTUNIDADE DE APRENDIZAGEM PARA AS ORGANIZAÇÕES NÃO GOVERNAMENTAIS: UM ESTUDO NA CIDADE DE RECIFE/PE
}

\author{
THE CONSULTING AS A LEARNING OPPORTUNITY FOR NON- \\ GOVERNMENTAL ORGANIZATIONS: \\ A STUDY IN THE CITY OF RECIFE / PE
}

\author{
Fernanda Bruto da Costa Correia ${ }^{1}$, Marcos Gilson Gomes Feitosa ${ }^{2}$ \\ e Naldeir dos Santos Vieira ${ }^{3}$
}

\section{Resumo}

As organizações não governamentais (ONGs) são instituições atuantes e em crescimento por todo o país e, a partir dos anos 1990, para se adequarem às contingências ambientais, começaram a se profissionalizarem, adotando práticas administrativas, como a gestão e a avaliação dos impactos de seus projetos. Assim, parte das ONGs passou a contratar profissionais que atuam como consultores organizacionais ou especialistas. Diante do exposto, o objetivo deste trabalho foi identificar e analisar os aprendizados que estão relacionados à prática de contratação de consultoria, obtidos pelas ONGs. Para tanto, foram realizadas entrevistas semiestruturadas com gerentes de ONGs que atuam na Região Metropolitana de Recife, PE, e que contrataram serviços de consultorias. Conclui-se que as ONGs, com a contratação de consultores, aprenderam que é necessário que estes profissionais conheçam e que tenham experiência de trabalho em organizações sociais, que entendam suas especificidades e que adotem uma metodologia que propicie um aprendizado reflexivo, sendo considerados como ineficazes aqueles que apenas implantam "pacotes" gerenciais pré-elaborados.

Palavras-chave: ONGs; Aprendizagem organizacional; Consultoria.

\footnotetext{
1 Mestre em Administração pela Universidade Federal de Pernambuco (UFPE). E-mail: fbccorreia@hotmail.com

2 Doutor em Educação pela Universidade Federal de São Carlos (UFSCAR). Prof. Adjunto da UFPE. E-mail: feitosam@terra.com.br

3 Mestre em Administração pela UFPE. Prof. Assistente da Universidade Federal do Piauí (UFPI). E-mail: naldeir@yahoo.com.br
} 


\begin{abstract}
Non-governmental organizations (NGOs) are active and growing institutions throughout the country, being from the 90s, to suit the environmental contingencies, are starting to professionalize, adopting administrative practices, such as management and evaluation of the impacts of their projects. Thus, part of NGOs started to hire professionals who act as consultants, which are organizational and specialists. In face of the above, the objective was to identify and analyze the learning, which are related to the practice of hiring consultants, obtained by NGOs. For both, there were semi-structured interviews with managers of NGOs that operate in the metropolitan area of Recife / EP and its contracted services of consultants. It appears that NCOs, with the hiring of consultants, learned that it is necessary that these professionals know and have experience of working in social organizations, who understand their specificities and to adopt a methodology which establishes a reflective learning, being regarded as ineffective those who only deploy "packages" managerial pre-prepared.
\end{abstract}

Keywords: NGO; Organizational Learning; Consulting.

\title{
1 Introdução
}

O que se faz e se pensa hoje nas organizações está muito relacionado ao trabalho criativo dos consultores organizacionais. As organizações não governamentais (ONGs) também estão entre essas organizações. Conforme Chapman (1998), os executivos de organizações sem fins lucrativos, constantemente expostos a desafios e problemas, têm trazido consultores para ajudar no desenvolvimento organizacional e nos processos de mudança. Essas organizações não apenas precisam fazer mais com menos recurso, como também estão inseridas num debate contínuo com respeito aos papéis, valores e transparência de suas organizações na sociedade moderna.

Scornavacca Jr. e Becker (2000, p. 15), entretanto, acrescentam que ainda há uma falta de qualificação e familiaridade com as especificidades destas organizações por parte dos profissionais, o que dificulta "o processo de transição da 'era do amadorismo' para a 'era do profissionalismo'". Dessa forma, afirmam os autores, para a implantação de projetos sociais bem estruturados, é necessário existirem profissionais qualificados atuando diretamente nas organizações ou sob a forma de consultorias.

Assim, cada vez mais as ONGs buscam incorporar conceitos e técnicas utilizados na administração, acrescentando à sua atividade instrumentos de gestão que assegurem o cumprimento dos seus objetivos institucionais com eficácia e eficiência. A consultoria, então, pode apresentar-se como um meio de ajuda na profissionalização das ONGs, o que de fato vem ocorrendo, com a contratação de empresas de consultorias ou consultores individuais.

Mesmo com toda expansão e consolidação da indústria de consultoria, de um lado, e a imensa difusão de críticas a ela, de outro, não há muitos estudos a respeito do seu modo de atuação no Brasil. A escassa literatura e a inexistência de pesquisa sobre o tema no país geram um interesse por esta questão. Mais escassas ainda são as pesquisas sobre consultoria organizacional nas organizações não governamentais. A profissionalização e o aprimoramento gerencial das ONGs já estão acontecendo; a contratação de consultorias com esse intuito também; o que falta agora são trabalhos que investiguem o assunto.

A questão, então, é como as consultorias têm influenciado as organizações não governamentais e o que estas têm aprendido sobre a contratação de consultoria, já que a pesquisa em administração ainda é escassa quanto aos procedimentos de gestão próprios dessas entida-

Rev. Adm. UFSM, Santa Maria, v. 3, n. 2, p. 245-259, mai./ago. 2010 
des e, provavelmente, os consultores venham com visões de mundo do mercado e/ou do Estado.

Assim, o presente trabalho pretende identificar e analisar os aprendizados das ONGs que estão relacionadas à prática de contratação de consultoria organizacional. Estudar a prática de consultoria em ONGs torna-se relevante, pois à medida que os consultores, nas ONGs, desempenham papéis de difusores de conhecimento gerencial e de apoio à elaboração de novos formatos organizacionais, desta relação depende a construção de organizações mais eficazes, mais abertas aos anseios dos cidadãos e, consequentemente, de uma sociedade mais bem atendida.

Ademais, a compreensão do tema pode ampliar as possibilidades de autorreflexão do consultor sobre a eficiência e eficácia do seu trabalho, da reflexão dos integrantes de ONGs sobre a decisão de contratar firmas de consultoria ou consultores, assim como de aumento do compromisso com a efetividade, essencial na atividade do consultor organizacional e das ONGs.

\section{Organizações não governamentais e sua gestão}

Apesar da assimilação de ONGs como sinônimo de entidades sem fins lucrativos, e ainda que designe uma característica geral do campo em questão, que é justamente sua natureza não-governamental, elas são reconhecidas como uma classe especial de entidades, dedicadas ao desenvolvimento participativo e sustentável, à construção da cidadania e defesa de direitos (OLIVEIRA; HADDAD, 2001), que exibem um reconhecimento em várias legislações nacionais e uma determinada forma de participação na ONU e outros sistemas internacionais regionais OEA, UNESCO, ECOSOC, Banco Mundial (ALARCÓN, 1999). Possuem, portanto, uma "gênese própria e não se confundem com entidades comunitárias e de auto-ajuda, como centros de pesquisa, fundações e entidades filantrópicas de corte tradicional". (OLIVEIRA; HADDAD, 2001, p. 63).

Ferreira (2005 apud TUDE; RODRIGUES, 2007, p.7) informa que, além das características consideradas inerentes às organizações do "terceiro setor", alguns estudiosos consideram que uma ONG deve atender a outro requisito: possuir função sócio-política. Desse modo, o que realmente distinguiria as organizações não governamentais das demais "são suas atividades fim, ou seja, o que, como, para quem e para que fazem".

Sendo assim, as ONGs não representam interesses particulares de grupos específicos, mas trabalham com causas que são tratadas universalmente. Mesmo desenvolvendo atividades assistenciais, reconhecem os limites destas atividades e procuram aliar a filantropia com mudanças sócio-políticas. Apesar de muitas ONGs serem religiosas, não buscam, em suas atividades, difundir determinado credo ou atrair fiéis para determinada igreja. E, por fim, as atividades fim dessas organizações não são de produção de bens para serem comercializados. Podem desenvolver atividades comerciais, como meio, ou seja, como forma para geração de recursos para a execução de suas atividades fim (TUDE; RODRIGUES, 2007).

Com isso, Tude e Rodrigues (2007, p.14) sintetizam que se pode dizer que as ONGs são "organizações da sociedade civil que lutam por determinada causa em nível universal, agindo politicamente, de maneira profissional com a finalidade de realizar transformações sociais em todo o planeta". Os autores adicionam ainda que a classificação como ONG exigiria juízo de valor, o que dificulta o seu reconhecimento jurídico e social.

Com as mudanças ao longo dos anos, na década de 1990, Fernandes (2002) afirma que as ONGs se viram diante de vários desafios, entre eles o de contribuir para o desenvolvimento 
macro - e não apenas limitar suas ações a microrregiões; tornarem-se mais transparentes, divulgando para o público o que são e o que pretendem; e serem mais participantes, ou seja, passarem da resistência à proposta. Desse modo, as ONGs dos anos 1990 começam a aprender a realizar suas atividades utilizando a linguagem dos "projetos", guiando suas ações por objetivos claros e quantificáveis, aliados a cronogramas controláveis (RODRIGUES, 1998).

No entanto, Alarcón (1999) faz algumas ponderações sobre certas debilidades das ONGs, isto é, a pequena envergadura de suas experiências e os reduzidos recursos disponíveis, o que causa défices nas suas capacidades técnico-profissionais, já que não podem contratar profissionais qualificados pelo tempo necessário, ferramentas de tecnologia da informação, bem como não podem contar com apoios logísticos e administrativos adequados.

Tude e Rodrigues (2007, p.14) afirmam que, para lutar pelas causas que acreditam e agir politicamente para realizar as transformações sociais necessárias, as ONGs procuram agir profissionalmente. Isto é, "desenvolveram e vêm desenvolvendo toda uma tecnologia para atingir tais fins sociais, e seus membros já executam tais atividades não mais somente como apaixonados e militantes, mas como profissionais".

Alguns autores, no entanto, fazem críticas à profissionalização da administração das ONGs da forma como vem sendo feita, isto é, fazendo uma incorporação acrítica e fora de contexto dos instrumentos originários do campo empresarial (THOMPSON, 2005; TENÓRIO, 1999).

Não é só a forma de atuar das ONGs que são modificadas com a profissionalização. Diniz (2000) afirma que os valores originais das ONGls, como altruísmo, promoção social, ajuda mútua, compaixão, voluntarismo, sensibilidade, solidariedade, direito à livre expressão e organização tendem a ser paulatinamente substituídos por valores de mercado, tais como competição, excelência empresarial, profissionalismo, individualismo, pragmatismo, foco nos clientes, eficiência e eficácia. No entanto, em contrapartida, as ONGls procuram "fortalecer o sentido de missão institucional e a vivência dos valores professados, como forma de garantir a preservação de sua identidade, enquanto $\mathrm{ONGl}$, e consequentemente sua sobrevivência organizacional" (DINIZ, 2000, p. 125).

Apesar da tentativa de distinção entre terceiro setor e ONG, os termos serão adotados ao longo da análise dos resultados como sinônimos, já que os próprios profissionais entrevistados se referiam utilizando os termos indiscriminadamente. Privilegiou-se o uso de ONG por se entender que as organizações pesquisadas possuíam características específicas de ONGs, principalmente no que se refere a não serem filantrópicas e a procurarem mudanças sócio-políticas mais profundas e o desenvolvimento participativo e sustentável.

\section{Relação consultor-cliente}

Várias são as perspectivas que retratam a relação consultor-cliente. Para Caldas (1996), o processo de consultoria, em tese, deveria ser concebido como uma relação de ajuda, um fornecimento de serviço profissional discreto, em um momento específico no tempo, de suporte especializado de um apoiador (consultor) a um apoiado (cliente).

Talvez a mais conhecida das imagens de consultoria na perspectiva de ajuda seja aquela que vê a relação como médico-paciente, popularizada principalmente por Schein (1972). Schein (1972) apresenta três modelos de consultoria: dois mais tradicionais, o modelo da compra de serviços especializados e o modelo médico-paciente, e um modelo que ele denomina de consultoria de processos (ou procedimentos, na tradução para português). 
Na compra de serviços especializados, o cliente define uma necessidade, algo que deseja saber ou alguma atividade que deseja realizar, e, em razão de a própria empresa não possuir tempo ou capacidade para tanto, contrata um consultor para satisfazer essa necessidade.

No modelo médico-paciente, a organização decide contratar um consultor ou uma empresa de consultoria para examiná-la, como um cliente que vai ao médico para um ckeckup. O consultor deve determinar o que está errado e recomendar um remédio, como um médico recomenda a um paciente.

Por fim, a consultoria de processos, que é definida por Schein $(1972$, p. 8) como um "conjunto de atividades desenvolvidas pelo consultor, que ajudam o cliente a perceber, entender e agir sobre fatos inter-relacionados que ocorrem no seu ambiente". Segundo o autor, os problemas serão resolvidos com maior eficiência e a solução apresentada permanecerá válida durante um maior tempo, se a própria organização indicar as soluções para os seus problemas.

Especificamente em relação à consultoria para organizações sem fins lucrativos, em estudo realizado com mais de cinquenta consultores, Chapman (1998) sugere que a consultoria de processo proposta por Schein (1972) é uma abordagem que pode ser usada em organizações sem fins lucrativos com grande efeito. O autor entende que esta abordagem, centrada no cliente, é apropriada a essas organizações, já que a colaboração e o envolvimento na tomada de decisões estão imbricados neste modelo de consultoria e coerente com as organizações sem fins lucrativos.

Chapman (1998) levanta, ainda, nas suas conclusões, algumas implicações para as organizações sem fins lucrativos na contratação de consultores. Entre elas, que os bons consultores irão ajudar a organização a identificar seus reais problemas e desafios e discutir um processo em conjunto para que seja possível uma mudança construtiva. Assim, deve-se ter cuidado com consultores que oferecem soluções prontas com uma abordagem não correspondente à situação. Também que a organização deve ser favorável a consultores que procuram compartilhar suas habilidades e conhecimento, a fim de ajudar a organização no sentido de aumentar sua capacidade de resolver seus problemas internamente e, consequentemente, num processo de aprendizagem contínua.

O aprendizado pode ser o obtido através de maneiras diferenciadas. Deste modo, a aprendizagem organizacional é entendida sob diferentes perspectivas, não existindo definição única para o que ela venha a ser, fazendo com que os conceitos variem de acordo com a visão de mundo de cada autor e com objeto estudado. Merrian e Caffarella (1999, p. 249) organizaram estes diversos pontos de vista sobre o processo de aprendizagem, agrupando-os em cinco orientações básicas: a behaviorista, a cognitivista, a humanista, a da aprendizagem social e a construtivista. Para Merrian e Caffarella (1999, p. 249), embora o aprendizado tenha sido definido numa variedade de formas, a maioria das definições inclui os conceitos de mudança comportamental e experiência. Uma definição comum dos psicólogos, especialmente aqueles que estavam investigando o fenômeno até os anos 1950, é que o aprendizado é uma mudança de comportamento.

Em um sentido amplo "a aprendizagem é um processo neural complexo, que leva à construção de memórias" (FLEURY; FLEURY, 2001, p. 27). Sob um entendimento mais convencional, Gherardi, Nicoli e Odella (1998, p. 274) afirmam que muitos estudiosos consideram que a aprendizagem ocorre através da internalização de algum tipo de conhecimento por meio da transferência da informação de uma fonte que a possui para o aprendiz.

A aprendizagem sobre a perspectiva do aprendizado social dá-se por meio das interações dos indivíduos. Esta perspectiva, para Merrian e Caffarella (1999, p. 259), "combina elementos tanto da orientação behaviorista como da cognitivista e apresenta uma posição de que as pesso- 
as aprendem observando as outras". Deste modo, um determinado grupo, formado por pessoas de backgrounds diferenciados, tende a um desenvolvimento de seus conhecimentos, uma vez que uma pessoa irá aprender com as outras, através da observação. Este aprendizado, baseado na observação, é comum entre os artesãos, passando de pai para filho a maneira de construir um objeto, ou em organizações, onde o detentor da expertise transfere seus conhecimentos para os novatos que o acompanha durante a realização das atividades.

Nesses grupos, os integrantes, sob uma visão behaviorista, são estimulados ao envolvimento e ao compartilhamento de experiência devido ao recebimento de benefícios, como gratificações e reconhecimento; ou de punições, como a exclusão do grupo. Assim, o interventor deve seguir a afirmação que diz: "reforce o que você quer que o indivíduo faça de novo, ignore o que você quer que o indivíduo pare de fazer" (GRIPPIN; PETERS, 1984, p. 65 apud MERRIAN; CAFFARELLA, 1999, p. 251).

Os indivíduos, estando ou não inseridos em grupos, têm insights e flashes, reorganizando uma determinada experiência por meio de estímulos do ambiente. Estes insights, derivados de um aprendizado cognitivo, tornam-se úteis para as organizações a partir do momento que são interpretados e compartilhados pelo grupo, subsidiando a resolução de problemas ou o desenvolvimento de produtos e da inovação.

No entanto, as pessoas, na perspectiva humanista, ao fazerem parte de um grupo, são responsáveis pelo seu crescimento e somente elas poderão ver sentido em suas ações perante o grupo. Deste modo, sua participação de maneira ativa ou passiva, colaborando ou não no compartilhamento de experiências com este grupo depende de suas escolhas e de seu estado interior. Merrian e Caffarella (1999, p. 256) falam que esta orientação considera que os seres humanos podem controlar seus próprios destinos; as pessoas são livres para agir, sendo o comportamento consequência da escolha humana.

Assim como a perspectiva humanista, a construtivista considera a aprendizagem como algo interno, sendo "um processo de construção de significados por parte do indivíduo e, dessa forma, uma atividade cognitiva interna" (MERRIAN; CAFFARELLA, 1999, p. 262).

Percebe-se, dessa maneira, que a aprendizagem de adultos, através da participação e envolvimento em determinados grupos, pode ser entendida sobre vários aspectos. É interessante entender estes enfoques, construindo um leque maior de explicações sobre como se dá a geração do conhecimento nesses grupos e qual postura o consultor deve seguir para facilitar o desenvolvimento de maiores aprendizados no sistema-cliente.

É a necessidade de conhecimentos e do desenvolvimento de aprendizados que faz com que os consultores sejam demandados pelas ONGs. A questão então é: ao contratar consultores, o que os integrantes das ONGs aprenderam sobre a prática de contratação de consultoria?

\section{Método}

Na presente pesquisa, foi adotada uma investigação de caráter qualitativo. O tipo de investigação qualitativa utilizada foi o estudo qualitativo básico ou genérico, que, segundo Merrian (1998, p. 11), "simplesmente busca descobrir e entender um fenômeno, um processo, ou as perspectivas e visões de mundo das pessoas envolvidas", em que os dados são coletados através de entrevistas, observações ou análise de documentos; as descobertas são um misto de descrição e análise e esta, geralmente, resulta na identificação de padrões recorrentes e não se estende para construir uma teoria. 
Assim, este trabalho enquadra-se como estudo qualitativo básico ou genérico porque se procurou identificar, nas ONGs pesquisadas, os elementos de aprendizados, fruto do trabalho de intervenção das consultorias organizacionais, analisando-se o fenômeno de forma a entender as perspectivas das pessoas envolvidas no processo de consultoria.

Ainda tendo em vista os objetivos do trabalho, foi realizada uma pesquisa de caráter exploratório, descritivo e interpretativo, localizando, na fala dos entrevistados, os aprendizados obtidos sobre o trabalho de consultoria realizado. Não existiu um teste de hipóteses prévias nesta investigação, de forma que se preservou a abertura para novos insights e visões da realidade.

Em relação ao método de coleta de dados, a pesquisa utilizou informações obtidas por meio de entrevistas semiestruturadas e em profundidade, com membros de três ONGs sediadas em Recife, PE. Foram entrevistados três membros, um de cada ONG, escolhidos de maneira intencional e não-probabilística. Segundo Patton (2002), o objetivo de uma amostra intencional é selecionar participantes que possam ser fontes de informações ricas para ajudar na iluminação das questões em estudo. Portanto, as pessoas entrevistadas foram escolhidas por terem participado ativamente de todo o processo de consultoria realizado na ONG.

Desse modo, neste estudo, foi analisado um pequeno grupo em um contexto específiCo, que jamais será representativo de toda a sociedade, sem qualquer intenção de generalizar, mas apenas como exemplo bem contextualizado. A pedido dos entrevistados, os seus nomes e os das ONGs não foram divulgados neste trabalho.

As pessoas foram entrevistadas em data e horário previamente agendados. Foi solicitada a permissão da gravação da entrevista, garantindo ao entrevistado a confidência das informações prestadas, que seriam utilizadas apenas para pesquisa acadêmica. Foram utilizados, durante as entrevistas, um caderno de anotações e um gravador para posterior transcrição.

Após a finalização da coleta dos dados, foi realizado o aprofundamento da análise e interpretação do material coletado. Entretanto, conforme Laville e Dionne (1999, p. 197), tal "análise e interpretação não são imediatamente possíveis". Desse modo, anteriormente, os dados foram organizados, sendo descritas as observações feitas e transcritas as gravações realizadas, ordenadas e agrupadas em categorias, de forma que fosse possível proceder às análises e interpretações que levaram às conclusões.

A análise de dados envolveu reduzir o volume de informação em seu estado bruto, peneirar os dados triviais dos mais representativos, identificar padrões importantes e construir uma estrutura para comunicar a essência do que os dados revelaram (PATTON, 2002). As análises, interpretações e conclusões foram realizadas com base nas categorias analíticas identificadas pelos pesquisadores deste estudo, sendo utilizado o método da constante comparação (MERRIAN, 1998) para análise e interpretação dos dados.

\section{Análise dos resultados}

\subsection{As ONGs pesquisadas}

As três ONGs pesquisadas têm perfis bastante diferenciados. Por se tratar de um estudo exploratório, esta diferenciação foi considerada interessante e enriquecedora, possibilitando que algumas interpretações fossem realizadas tendo em vista o perfil de cada ONG.

A ONG 1 é uma filial de uma organização não governamental internacional (ONGI), que possui no seu escritório de Recife 20 funcionários, tendo no total 4.000 funcionários no 
mundo todo. Esta ONG atua em diversas áreas, como educação, geração de trabalho e renda, micro-crédito, cultura, apoio às comunidades rurais e indígenas, entre outras. A pessoa entrevistada é Gerente de Administração e Finanças, que além de participar diretamente dos processos de consultoria, também é responsável pela contratação das mesmas e está na organização desde 2003. Esta ONG contrata consultorias com conhecimentos em execução de projetos, em facilitação, definição de objetivos e estratégias e avaliação de projeto.

A ONG 2 é uma extensão de uma ONGl, seu foco é buscar recursos para o apoio de ONGs menores que atuam na área de micro-crédito, possuindo 93 funcionários. A entrevistada trabalha desde 2005 e também é Gerente de Administração e Finanças. Esta ONG contrata consultoria para planejamento financeiro e operacional, consultoria especializada em treinamento de pessoas, e consultoria jurídica.

A ONG 3 tem um porte menor que as anteriores, com 18 funcionários. A pessoa entrevistada é, atualmente, Coordenadora de Marketing, mas está na instituição desde 1998 e já foi presidente da mesma. O foco da instituição é proporcionar a melhoria da qualidade de vida de crianças carentes que precisam de ajuda para a sobrevivência. Esta ONG contratou consultoria organizacional para elaboração de reformas estatutárias e consultoria especializada em seleção de funcionários.

\subsection{A consultoria organizacional como um ponto de partida para no- vas aprendizagens}

A consultoria organizacional foi considerada como um ponto de partida para a aprendizagem dos membros das ONGs, sendo esta percebida como um estímulo à busca de novos conhecimentos. Neste sentido, o aprendizado talvez não tenha vindo diretamente da consultoria, na forma de um conhecimento técnico sobre determinado assunto ou um método de trabalho, mas a sua forma de trabalhar provocou os membros das ONGs a buscarem novos conhecimentos e, consequentemente, novos aprendizados. O aprendizado, neste contexto, pode até vir a ser contrário às ideias da consultoria ou no sentido de favorecer a busca de conhecimentos em outras fontes, conforme afirmam os entrevistados:

\footnotetext{
Na verdade, eu não sei te explicar, mas não é um aprendizado que vem tão diretamente da consultoria, mas ela te levanta... [...] Os meus aprendizados foram sempre provocativos. Ela mostra a forma de você fazer as coisas, você às vezes nem concorda com aquilo, aí vai buscar informação e junta com aquilo e o aprendizado final é maior... (ONG 1).

[...] o fato da consultoria ter acabado me fez buscar outras fontes de conhecimento, de informação que não só a consultoria. A consultoria, digamos assim, foi só o primeiro estalo pra que depois a gente fosse buscar [conhecimento] em outros lugares. (ONG 2).
}

Eu acho que a consultoria foi um marco de divisão. Ela plantou a sementinha... (ONG 3).

Essas afirmações estão de acordo com entendimento de Schein (1972, p. 8) sobre a prática de consultoria, pois, para este, ela é mais do que um processo de transmissão de conhecimento, ela deve ajudar o cliente a perceber, entender e agir sobre fatos inter-relacionados que ocorrem no seu ambiente. Nessas ONGs, de acordo com as entrevistadas, ocorreu uma mudança na percepção dos clientes. 


\subsection{A experiência da ONG com a contratação de consultoria}

Várias experiências vivenciadas pelos membros das ONGs, durante e após o processo de consultoria, que resultaram em aprendizado, fruto de reflexão, foram identificadas na pesquisa. Os aprendizados que tinham semelhanças entre si foram agrupados e, para facilitar a análise e o entendimento, optou-se por transformá-los nos tópicos subsequentes.

\subsubsection{O conhecimento do consultor sobre o "terceiro setor"}

Exceto na ONG 3, o conhecimento do consultor sobre o "terceiro setor" foi um ponto bastante crítico na visão dos entrevistados. A partir das reflexões de experiências negativas ocorridas com consultorias organizacionais, os membros das ONGs 1 e 2 aprenderam que o conhecimento do consultor sobre o "setor é essencial", já que este possui características peculiaridades, diferenciadas do mercado e do Estado. Este conhecimento necessário, no entanto, não se refere especificamente ao "negócio" da ONG, mas sobre a realidade do "terceiro setor", suas práticas.

A questão da linguagem foi bastante enfatizada. As palavras utilizadas pelas ONGs também são diferenciadas do vocábulo próprio do mercado. Assim, apesar de o "terceiro setor" estar incorporando "o jargão típico do mercantilismo, tais como marketing, outsourcing, merchandising, resizing e outros do gênero" (THOMPSON, 2005, p. 46), estas palavras ainda não são bem vistas pelas ONGs. Para as organizações pesquisadas, os processos de consultoria realizados com consultores que utilizam essa linguagem durante o trabalho têm sido experiências negativas. As entrevistadas enfatizam claramente este aspecto:

\footnotetext{
Uma segunda experiência negativa é quando a consultoria não entende nada sobre o terceiro setor. Então ela fica fazendo perguntas esquizofrênicas que não têm nada a ver com o dia-adia da gente e acaba que a comunicação sai partida, a gente fala e ela não entende também, é uma questão de linguagem mesmo, a gente tem uma forma de linguagem, ela tem outra, então não entende, a compreensão não acontece (ONG 2).
}

[...] palavras que lembrem o capitalismo são totalmente palavrão. [...] Então o consultor precisa conhecer o setor para que ele use vocabulário adequado, senão o processo fica impactado. Você fica prestando atenção nas palavras que ele está usando e não presta atenção no que precisa fazer [...] [em uma consultoria] esse consultor usou palavras como 'maximizar', palavras como 'obter resultado', como 'satisfazer o cliente' [...] quando acabou, as críticas foram muito forte ao palavreado, 'isso parecia um show biz' [...] O aprendizado é que não vamos contratar mais. Então, agora, quando eu vou contratar, eu presto mais atenção na forma como a pessoa fala, mesmo que ela jure por Deus que vai mudar, eu não contrato. A pessoa tem que estar usando o palavreado adequado, ter essa sensibilidade (ONG 1).

Assim, conhecer o "terceiro setor" passou a ser um critério para a contratação da consultoria. "Não adianta ser uma consultoria que nunca prestou serviços, vamos dizer assim, ou cujos membros que fazem parte da consultoria nunca tenham tido acesso à realidade do 'terceiro setor'. É muito diferente, vamos dizer assim, as práticas são um pouco diferente do que se faz normalmente" (ONG 2). "Essa é a maior dificuldade que a gente tem hoje, porque experiência com o setor de ONGs, não digo que tem que entender o que faz uma ONG, mas esse setor tem peculiaridades ainda não reconhecidas pelo mercado" (ONG 1). 
Baseando-se em Thompson (2005) e Tenório (1999), pode-se afirmar que contratar consultores que não conhecem a realidade do "terceiro setor" pode provocar causas indesejáveis, pois as práticas administrativas não devem ser implantadas nas ONGs de maneira acrítica e fora de contexto dos instrumentos originários do campo empresarial. Para estes autores, as especificidades deste setor devem ser consideradas durante a intervenção.

Na ONG 3, esta questão, a princípio, não foi considerada importante, talvez pelas características da instituição. Isto é, por ser uma instituição bastante antiga (47 anos de existência), ocorreram muitas mudanças de direção, normalmente entre os familiares dos fundadores. Essas sucessões, no entanto, não ocorriam de forma planejada e nem a ONG tinha sua missão e objetivos bastante consolidados, ocorrendo que a cada mudança de gestão, os novos dirigentes entravam com visões diferentes da gestão anterior. Assim, continuando este padrão de mudança de visão dos dirigentes, os atuais vieram de uma cultura empresarial e estão reorganizando a forma de trabalhar da ONG de acordo com suas visões de mundo, o que talvez explique a pouca importância dada ao conhecimento do consultor sobre o setor na pesquisa realizada no contexto atual.

\subsubsection{Necessidade de deixar claro o papel do consultor e do cliente no processo de consultoria}

Da pesquisa realizada, percebeu-se que os trabalhos de consultoria realizados nas ONGs tiveram um método de trabalho semelhante, no sentido do consultor e do cliente desenvolverem em conjunto as atividades, através de reuniões entre o consultor e uma pessoa da equipe da ONG ou entre o consultor e um grande grupo, bem como através de facilitações de processo. O plano de trabalho da atividade de consultoria e o desenvolvimento dessas atividades são, então, construídos em conjunto com o consultor e o cliente. Para que gere os resultados esperados, as ONGs afirmaram que esse entendimento é essencial.

Neste contexto, o consultor é mais um mediador e facilitador da construção do conhecimento pelos membros da ONG do que propriamente o responsável por fazer o trabalho. A aprendizagem das ONGs com os consultores, então, vão ao encontro do entendimento de Gonçalves (1991) de que a ação de consultoria depende mais do cliente do que do próprio consultor. Existem também momentos em que o consultor trabalha de forma isolada, quando escreve um relatório, por exemplo, e, mesmo nesse caso, acontece deste relatório depois passar por uma avaliação por parte das ONGs, que pode manter ou alterar o resultado final:

\footnotetext{
Existem também momentos que a consultoria desenvolve, trabalha sozinha [...] mas sempre passa por nossa revisão. A gente nunca deixa que a consultoria chegue ao final sem antes passar por uma revisão nossa ou contextualizar às vezes as coisas (ONG 2).

Já fizemos, por exemplo, sistematização de resultado que quando chegou o relatório final a gente vê claramente que têm problemas [...] não que a gente não quer concordar com o relatório, mas que o relatório esta dizendo uma coisa de uma forma que não vai traduzir o real aprendizado que deveria traduzir. Então a gente tem que negociar no final, acertar com o consultor para ele mudar a forma daquilo que está escrito [...] (ONG 1).
}

O entendimento do papel do consultor no processo de consultoria, portanto, é um aprendizado fruto dos trabalhos já desenvolvidos com consultores que se mostraram ineficazes quando não havia essa clareza. Na percepção dos membros das ONGs, precisa ficar claro, 
desde o início, qual o papel das partes durante a consultoria e que, indiretamente, influencia o pós-consultoria. Para as ONGs, o trabalho tem que ser desenvolvido por elas. O consultor não é entendido como "o" responsável pelo resultado final, mas como um facilitador.

\footnotetext{
Inclusive a gente tem muito medo disso, de uma consultoria entrar, dar um tipo de opinião que não deveria dar, ou entrar para outro campo que não seria o campo específico que a gente quer, para desfocar a ação dela da atividade. [...] a gente não entende consultor como aquela pessoa que vem entrega o produto e tchau, mas aquela pessoa que vem, entrega o produto e ensina as pessoas-chaves a fazerem o que se está pretendendo (ONG 2).

[...] a gente deixa claro para o consultor que tudo que a gente não quer é a opinião dele. [...] A gente não quer a opinião do consultor, a gente quer que ele faça a gente pensar. [o consultor que chega com opinião e não estimula o cliente a pensar] eu acho que atrapalha bastante [...] eu já vi isso acontecer, de experiência, de prejudicar, de levar as pessoas por um caminho totalmente equivocado (ONG 1).
}

Além disso, por ser um setor com peculiaridades, mesmo que o consultor tenha conhecimento sobre o "terceiro setor", o que é essencial, não garante que ela entenda sobre aquela determinada ONG. Por conta da diversidade e precária precisão de definições conceituais sobre o que são ou fazem essas entidades (SALAMON, 1998; FISCHER; FALCONER, 1998; MADEIRA; BIANCARDI, 2003; RODRIGUES, 1998), torna-se difícil para as consultorias se especializarem no objeto de interesse de cada ONG.

Porque nesse mundo das ONGs, ele é um mundo muito vasto, não é como você estar num banco e contratar uma consultoria que entenda de banco, ou você está no varejo e contratar uma consultoria que entenda de varejo, daqui que você vá contratar um consultor que entenda de ONG, ele pode ter vários vieses. [...] Então, a coisa mais importante é que ele não traga a opinião dele, mas ele facilite o processo. A gente define isso com o consultor (ONG 1).

Apesar desse aprendizado de que precisa ficar claro o papel do consultor, e de que o trabalho será principalmente desenvolvido pelo cliente, ocorreram alguns problemas nas ONGs 2 e 3, quando da saída do consultor, com referência à continuidade na implantação das decisões oriundas do trabalho de consultoria. Já na ONG 1 isso não ocorreu, porque o aprendizado de que o trabalho de consultoria é desenvolvido pela equipe da ONG e não pelo consultor é uma questão internalizada por todos.

Outros aspectos destacados, com relação aos papéis, foram em relação ao tempo da consultoria e do cliente dedicado ao processo de consultoria e o envolvimento do consultor no processo. Assim, a experiência em consultorias organizacionais mostrou que nem sempre é possível dedicar o tempo necessário para a realização das atividades, seja por parte dos próprios membros da ONG, que não compareciam sempre (no caso da ONG 3), seja por parte dos consultores, que não tinha a disponibilidade de tempo esperada (no caso da ONG 2).

Com relação ao envolvimento do consultor no processo, esse foi um aprendizado relacionado ao papel do consultor especificamente, já que se entende que ele não pode se envolver demais no processo, tomando partido de um ou outro membro e, até, discriminando a visão de outros participantes da equipe da ONG. 


\begin{abstract}
Dependendo da experiência do consultor, ele pode se envolver demais no processo. Por mais que ele queira ser isento, ele acaba tomando partido de alguns grupos. É a pior coisa que pode acontecer num processo de consultoria [...] Tem momentos que a gerência está preparada para lidar com isso [...] e tem momentos que a gerência é influenciada pelo consultor também, ou se deixa influenciar ou também concorda com o consultor de forma que uma determinada pessoa da equipe pode ficar numa situação muito difícil diante do processo. Eu já presenciei isso. [...] É a pior postura que um consultor pode ter (ONG 1).
\end{abstract}

\title{
5.3.3 A importância da visão do consultor
}

Apesar do entendimento de que o cliente é que desenvolve o trabalho e o consultor facilita, a visão diferente desse é essencial na atividade. Isso quer dizer que os membros das ONGs têm refletido sobre as experiências com consultores que veem com visões diferentes e isso têm gerado um aprendizado importante. A diferença de visão do consultor se refere a vários aspectos. O consultor pode enxergar a situação de uma forma mais ampla, com outra visão do problema, ampliando o entendimento e inserindo variáveis diferentes das dos membros da equipe da ONG. Do mesmo modo, ele também pode ter um entendimento mais completo sobre todos os aspectos que envolveriam o trabalho de consultoria e que não foram anteriormente previstos pela ONG.

[...] quando você está dentro do problema você não vê. Se vem uma pessoa de fora, a pessoa de fora enxerga [...] (ONG 3).

Sempre durante o processo de consultoria, acaba que a consultoria amplia muito mais o escopo e o objetivo do que estava previamente planejado. [...] a gente não consegue dimensionar todos os fatores que influenciam o processo de consultoria [...] Eles [os consultores] olham a organização de forma diferente, como eles chegam com um olhar de fora, eles conseguem ver incoerências na organização que a gente, por estar envolvido na atividade do dia-a-dia, a gente não consegue (ONG 2).

E têm alguns que você percebe que eles têm uma visão, que eu chamo de visão de helicóptero, eles não ficam no meio da floresta perdidos como nós [...] (ONG 1).

Na ONG 1, inclusive, que já tem uma prática e uma disponibilidade de recursos para contratar consultorias, foi considerado que começa a haver uma diferença entre aquelas pessoas que trabalham com consultoria daquelas que não trabalham. Segundo a entrevistada, as pessoas que costumam trabalhar conjuntamente com os consultores têm uma visão de mais longo prazo, conseguem vislumbrar melhor novos aspectos, novas frentes de trabalho e necessidades não percebidas pelos que não trabalham com consultorias, ou seja, têm uma visão mais ampliada de uma situação, já que está em contato com pessoas que apresentam outras possibilidades de pensar.

No entanto, foi destacado, ainda, que é possível diferenciar bons e maus consultores durante o processo de consultoria. Os primeiros estimulariam o pensamento e o aprendizado dos clientes, enquanto os segundos tentariam impor sua opinião, o que prejudicaria a aprendizagem. 
[...] tem consultor que ele te faz pensar mais, te faz perguntas, "por que isso? [...] por que você acha que assim está certo? [...] E tem consultor [...] que não é tão preocupado com essa forma. Então eu acho que os consultores que fazem mais perguntas, não porque não sabem, porque às vezes não sabem mesmo e também não precisa saber, mas ele levanta em você dúvidas que faz você pensar e crescer em relação aquilo [...] (ONG 1).

Nota-se que, nas ONGs, é extremamente valorizado o consultor que assume uma postura construtivista durante a intervenção, sendo esta "um processo de construção de significados por parte do indivíduo e, dessa forma, uma atividade cognitiva interna" (MERRIAN; CAFFARELLA, 1999, p. 262). Assim, estes consultores não apenas transferem o conhecimento para o cliente (GHERARDI, NICOLI; ODELLA, 1998, p. 274), mas também estimulam a reflexão.

\section{Considerações finais}

Percebe-se, por meio das entrevistas dos integrantes das ONGs pesquisadas, que a contratação de consultoria é uma prática considerada como necessária, mas que deve ser realizada tomando-se certos cuidados.

O primeiro deles é contratar um consultor que tenha experiência em consultoria com ONGs e que conheça a realidade do chamado terceiro setor, para que não proponha práticas equivocadas, que possam ser úteis para as organizações mercantis, porém inapropriadas para as ONGs.

Outro fator considerado como relevante pelas entrevistadas é a contratação de consultores que busquem desenvolver um aprendizado reflexivo, que não somente transmitam conhecimentos, mas que facilitem a reflexão de seus clientes, gerando novos aprendizados que facilitarão a tomada de decisão.

Por fim, as entrevistadas alertaram para a necessidade das ONGs e do consultor deixarem claro qual será o papel de cada um no processo de consultoria. Desse modo, poderão ser evitadas distorções neste processo, evitando também a manipulação das decisões da diretoria por parte do consultor.

Outro ponto relevante é a visão do consultor que, por ser um agente externo às ONGs, tem uma visão mais ampliada e menos enviesada sobre a realidade da mesma, podendo estimular novas discussões a partir de uma nova ótica que pode ajudar na resolução de problemas.

Nota-se que as ONGs também têm algumas críticas à prática de consultoria, sendo que parte delas se diferenciam das citadas por estudiosos da área (CALDAS et al., 1999; WOOD JR.; PAES DE PAULA, 2004; WOOD JR.; CALDAS, 2005; GONÇALVES, 1991 ). Este fato pode ser explicado pela presença de características específicas do "terceiro setor" nas ONGs, uma vez que as críticas dos autores acima são, basicamente, resultado das atuações dos consultores em organizações do "segundo setor". Portanto, não se pretende, com este trabalho, defender a contratação de consultores como uma prática que deve ser adotada pelas ONGs, e sim que esses profissionais podem ser úteis para o desenvolvimento de novas práticas nestas instituições que a cada dia desenvolvem projetos com maiores extensões, movimentando um grande volume de recursos financeiros. No entanto, este trabalho alerta para o fato de que certos cuidados devem ser tomados ao contratar estes profissionais, tornando-se útil para outras ONGs que estão em fase de contratação de consultoria. 
Por fim, a presente pesquisa não se esgota em si mesma, sendo, muito pelo contrário, geradora de novos questionamentos e desafios futuros. Desse modo, sugere-se ampliar o número de ONGs estudadas, assim como o número de entrevistados em um próximo estudo, já que a realização de três entrevistas foi uma limitação deste.

\section{Referências}

ALARCÓN, Sérgio. Eje Temático del documento "Ciudadanía Social": perspectivas de las organizaciones no gubernamentales. Disponível em: http://www.fas.harvard.edu/ drclas/programs/ PASCA/pdfs/spanish/Chile\%201999/Ciudadania/Sergio-Alarc=n.pdf. Acesso em: 02 fev. 2007.

CALDAS, Miguel et al. Um gostinho do próprio remédio: até que ponto empresas de consultoria no Brasil adotam em si mesmas aquilo que prescrevem a seus clientes? RAE Light, v. 6, n. 4, p. 2-12, out./ dez. 1999.

CALDAS, Miguel P. Toward a more comprehensive model of managerial innovation difusion: why consultants are not the only ones to blame. In: ANNUAL MEETING OF THE ACADEMY OF MANAGEMENT. Anais ... Cincinnati (EUA), 1996.

CHAPMAN, Judith. Do process consultants need different skills when working with nonprofits? Leadership \& Organization Development Journal, v. 19, n. 4, p. 211-215, 1998.

DINIZ, João Helder A. da S. O reflexo dos ajustes das organizações não-governamentais internacionais: ONGls, às modernas práticas administrativas, sobre o seu caráter institucional-original. 2000, 147f. Dissertação (Mestrado em Administração)-Universidade Federal de Pernambuco, Pernambuco, 2000.

FERNANDES, Rubem César. Privado porém público: o terceiro setor na América Latina. Rio de Janeiro: Relume-Dumará, 2002.

FISCHER, Rosa Maria; FALCONER, Andrés Pablo. Desafios da parceria governo e terceiro setor. Revista de Administração da USP - RAUSP, São Paulo, v.33, n.1, p. 12-19, jan./mar. 1998.

FLEURY, A.; FLEURY, M. A competência e aprendizagem organizacional. In: _. Estratégias empresariais e formação de competências: um quebra-cabeça caleidoscópio da indústria brasileira. 2. ed. São Paulo: Atlas, 2001. p. 17-33.
GHERARDI, S.; NICOLINI, D; ODELLA, F. Toward a social understanding of how people lean in organizations. Management Learning, v. 29, n. 3, p. 273-297, 1998.

GONÇALVES, Marilson Alves. Consultoria. Revista de Administração de Empresas, São Paulo, v.31, n.2, p.91-98, abr./jun. 1991.

LAVILLE, Christian; DIONNE, Jean. A construção do saber: manual de metodologia da pesquisa em ciências humanas. Porto Alegre: Artes Médicas; Belo Horizonte: Ed. da UFMG, 1999.

MADEIRA, Felícia Reicher; BIANCARDI, Miriam Ribeiro. O desafio das estatísticas do terceiro setor. São Paulo Perspec., São Paulo, v. 17, n. 3-4, 2003. Disponível em: <http://www.scielo.br/ scielo.php?script $=$ sci_arttext\&pid $=$ S0102$88392003000300018 \& \operatorname{lng}=$ pt\&nrm $=$ iso $>$. Acesso em: 18 nov. 2006.

MERRIAN, S. What is qualitative research? In: Qualitative research and case study applications in education. San Francisco: Jossey-Bass, 1998. p. 325.

MERRIAN, S.; CAFFARELLA, R. Learning in adulthood: a comprehensive guide. 2. ed. San Francisco: Jossey-Bass, 1999.

OLIVEIRA, Anna Cynthia; HADDAD, Sérgio. As organizações da sociedade civil e as ONGs de educação. Cad. Pesqui., São Paulo, n. 112, 2001. Disponível em: <http://www.scielo.br/ scielo.php?script $=$ sci_arttext\&pid $=$ S0100 $>$. Acesso em: 18 nov. 2006.

PATTON, M. Qualitative research and evaluation methods. 3. ed. Thousand Oaks: Sage, 2002.

RODRIGUES, M. C. P. Demandas sociais versus crise de financiamento: o papel do terceiro setor no Brasil. Revista de Administração Pública, Rio de Janeiro, v.32, n.5, p.25-67, set./out. 1998. 
SALAMON, Lester. A emergência do terceiro setor: uma revolução associativa global. Revista de Administração da USP - RAUSP, São Paulo, v.33, n.1, p. 511, jan./mar. 1998.

SCHEIN, Edgar H. Consultoria de procedimentos. São Paulo: Edgard Blucher, 1972.

SCORNAVACCA JR, Eusébio; BECKER, João Luís. Há vagas? A inserção dos administradores no terceiro setor. READ, ed.13, v.6, n.1, jan-fev, 2000. p. 117.

TENÓRIO, Fernando G. Um espectro ronda o terceiro setor: o espectro do mercado. Disponível em: $<$ http://www.fas.harvard.edu/ drclas/programs/ PASCA/pdfs/spanish/Chile\% 20/1999/Ciudadania/ Fernando-Tenorio.pdf > . Acesso em: 27 nov. 2006.

THOMPSON, Andrés. Do compromisso à eficiência: os caminhos do terceiro setor na América Latina. In: IOSCHPE, Evelyn (Org.). Terceiro setor: desenvolvimento social sustentado. São Paulo: Paz e Terra, 2005. p. 41-48.

TUDE, João; RODRIGUES, Grace K. M. Organizações não governamentais: uma discussão sobre suas peculiaridades organizacionais. In: Conferência Regional de ISTR para América Latina y el Caribe, 6., 2007, Salvador. Anais Eletrônicos... Salvador: ISTR y CIAGS/UFBA, 2007.

WOOD Jr., Thomaz; CALDAS, Miguel P. Rindo do quê? Como consultores reagem ao humor crítico e à ironia sobre sua profissão. Revista Organização \& Sociedade, Salvador, v.12, n. 34, p. 83-101, jul./set. 2005.

WOOD Jr.; PAES DE PAULA, Ana P. Empresas de consultoria: um estudo múltiplo de casos. In: ENCONTRO NACIONAL DOS PROGRAMAS DE PÓSGRADUAÇÃO EM ADMINISTRAÇÃO (ENANPAD), 28., 2004, Curitiba. Anais eletrônicos... Curitiba: ANPAD, 2004. 